Facsimile Price $\$ 2,60$
Microfilm Price $\$$
Available from the
Office of Technical Services
Department of Commerce
Washington 25, D. C.

\section{TID. 18816}

SCDC-2046

THE CONVERSION OF ELECTROMAGNETIC ENERGY INTO SHOCK PULSES

T, F. Meagher, 8121-2

Sandia Corporation

Livermore Laboratory

May 1963

\begin{abstract}
ABSTRAC'T
The repulsion-coil technique for energy conversion offers a powerful, new tool in the field of acceleration testing. Using this technique, a prototype magnetic shock device was developed that uses electrical energy stored in a capacitor bank to produce high-g, mechanical acceleration pulses.

A disc projectile is vacuum-held against the core of an electromagnet coil, and a crystal accelerometer is attached to the projectile to monitor the pulse. The capacitor bank is charged to a specific voltage between one and $20 \mathrm{kv}$, then discharged into the coil. The resultant magnetic field around the coll effects a repulsion of the projectile, which is mechanically free to move away from the coil. By varying the capacitor voltage, the magnitude of the pulse can be predicted and controlled.

This investigation is intended to demonstrate the application of electricalenergy conversion in the production of a controllable acceleration pulse, toward development of a magnetic shock device for component testing and instrument calibration.
\end{abstract}

Note: This document is not to be reproduced in whole or in part without written permission by the supervisor of the originating division. 


\section{DISCLAIMER}

This report was prepared as an account of work sponsored by an agency of the United States Government. Neither the United States Government nor any agency Thereof, nor any of their employees, makes any warranty, express or implied, or assumes any legal liability or responsibility for the accuracy, completeness, or usefulness of any information, apparatus, product, or process disclosed, or represents that its use would not infringe privately owned rights. Reference herein to any specific commercial product, process, or service by trade name, trademark, manufacturer, or otherwise does not necessarily constitute or imply its endorsement, recommendation, or favoring by the United States Government or any agency thereof. The views and opinions of authors expressed herein do not necessarily state or reflect those of the United States Government or any agency thereof. 


\section{DISCLAIMER}

Portions of this document may be illegible in electronic image products. Images are produced from the best available original document. 


\section{ACKNOWLEDGMENTS}

Mr. Kenneth D. Marx, Sandia Corporation, Livermore Laboratory, Test Design Division 8127, who aided the author in developing the original idea.

Dr. H. P. Furth, Lawrence Radiation Laboratory, Livermore, for assistance in theoretical aspects.

Mr. D. H. Birdsall, Lawrence Radiation Laboratory, Livermore, for construction ideas and hardware.

Mr. A. R. Harvey, Lawrence Radiation Laboratory, Livermore, for coil design and fabrication. 
CONTENTS

\section{Page}

THE CONVERSION OF ELECTROMAGNETIC ENERGY INTO SHOCK PULSES

Introduction

Field Analysis

Magnetic Field Force

Test Setup

Description

Operation

Instrumentation

Results and Conclusions

Test Results

Limiting Factors

Force Amplitude

20

Force Width

20

Conclusions

APPENDIX A -- REFERENCES

APPENDIX B -- CIRCUIT THEORY

APPENDIX C -- FIELD ENERGY THEORY 


\section{ILLUSTRATIONS}

Figure

Page

1 Prototype Magnetic Shock Device

2 Basic Current-Field/Induced-Current Relationship

3 Block Diagram of Capacitor Bank and Controls

$4 \quad$ Encapsulated Magnet

$5 \quad$ Simplified Diagram of Test Setup

$6 \quad$ Test Setup

$7 \quad$ Cross-Section Showing Current and Field Relationship of Magnet and Projectile

8

Field-Current-Force Relationship

$9 \quad$ Unfiltered Acceleration Pulses at Various Input Voltages 


\title{
THE CONVERSION OF ELECTROMAGNETIC ENERGY INTO SHOCK PULSES
}

\author{
Introduction
}

This report describes an investigation into the properties and use of stored electrical energy and its conversion to mechanical energy. The investigation stems from a need at Sandia Corporation, Livermore Laboratory, for a mechanical shock-test facility capable of controlled acceleration magnitude and duration, covering the range of $100,000-\mathrm{g}$ acceleration with a 100 microsecond duration, to a $20,000-g$ pulse with a one-millisecond duration (assuming a one-pound test package).

This report provides the theory, description, and test results of a prototype shock device, based on a theory of electromagnetic repulsion, using electrical energy stored in a capacitor bank. be:

Primary requirements for a sophisticated test device were determined to

1. Variable-acceleration pulse amplitude and width

2. Accurate repeatability

3. Freedom from mechanical noise

Forces attainable from high-magnitude, transient, magnetic fields have been used in a variety of ways, most notably in plasma "pinch" experiments. Industry uses transient magnetic fields in many metal-forming applications requiring high force. It was determined that these same forces could be used to produce high-g, mechanical acceleration pulses.

Theory

Primary elements of the magnetic shock device (Figure 1) include electrical energy stored in capacitor banks and the repulsion coil mounted in the test enclosure. Basic principles involve the conversion of the energy stored in the capacitors into mechanical kinetic energy. Energy is converted by discharging the capacitor bank through the coil, which creates a time-varying magnetic field. The field reacts against a conductor (projectile) located close to the coil windings causing the projectile to accelerate rapidly away from the coil.

To determine the force of acceleration on the moving projectile, three basic theoretical approaches are available: Circuit theory, field energy theory, 


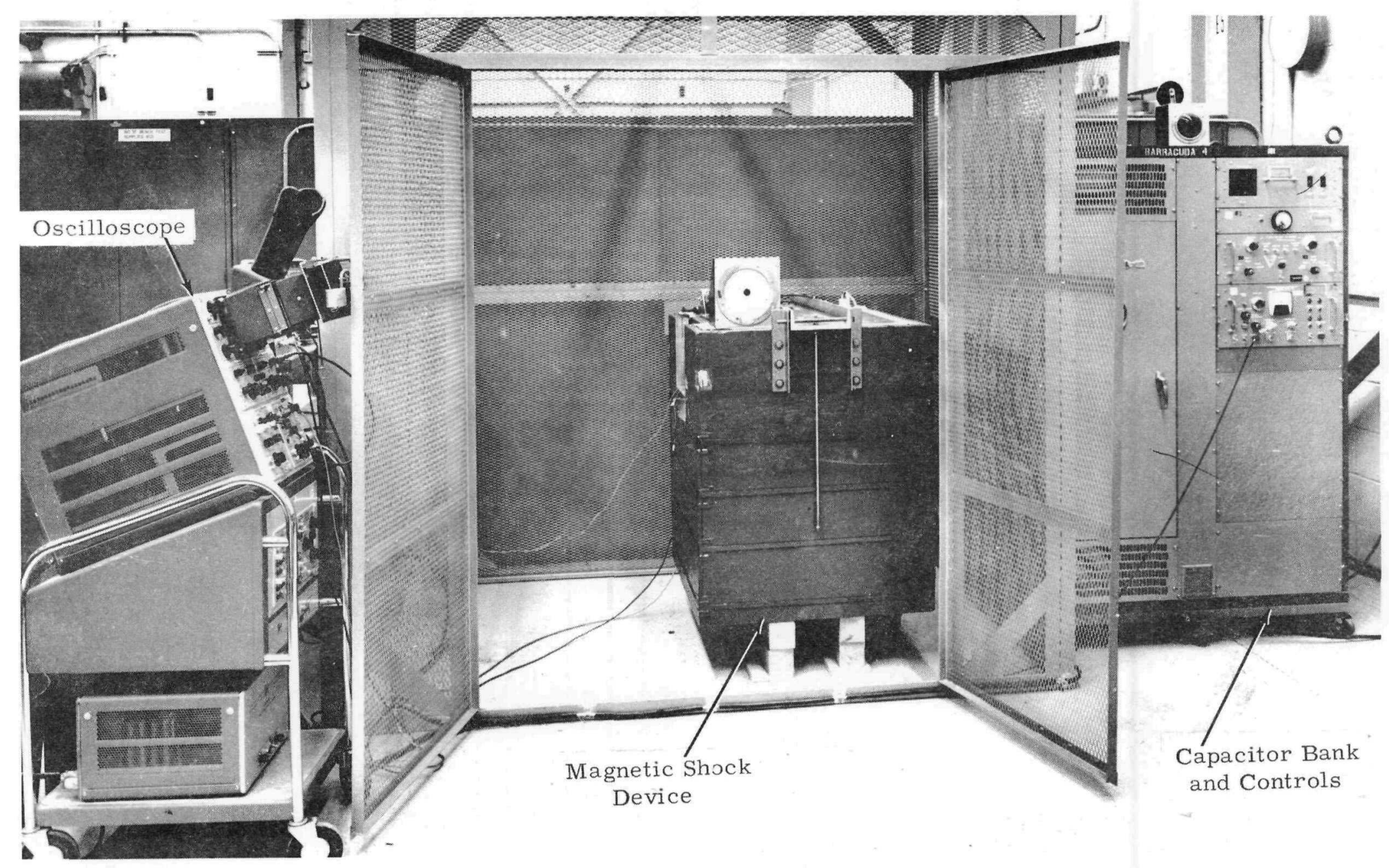

Figure 1. Prototype Magnetic Shock Device 
and field analysis theory. For this report, the field analysis theory has been developed in greatest detail. This approach seemed to offer the clearest physical explanation of the mechanics of deriving a mechanical force from an electromagnetic field. The remaining theories are discussed briefly in Appendixes B and $\mathrm{C}$ as they apply to this investigation.

\section{Field Analysis}

Referring to Figure 2, consider a sheet of oscillating current flowing into the paper in the vicinity of a conductor. Let the current sheet and the conductor be very wide such that edge effects may be neglected. This current sheet gives rise to a magnetic field around the current sheet. In the air gap between the coil and the conductor, the magnetic field is represented by the magnetic intensity vector $\overline{\mathrm{H}}_{\mathrm{O}}$. The time varying magnetic field will induce a current flow in the conductor at the frequency of the magnetic field. The depth of current into the conductor (Reference 1) is expressed as follows:

$$
\delta=\frac{1}{\sqrt{\pi \mathrm{f} \mu \sigma}} .
$$

Where $\delta$ is the skin depth of the current penetration in meters and $f$ is the frequency in cycles per second, $\mu$ is the permeability of the conductor in henries/ meter and $\sigma$ is conductor conductivity in mhos/meter.

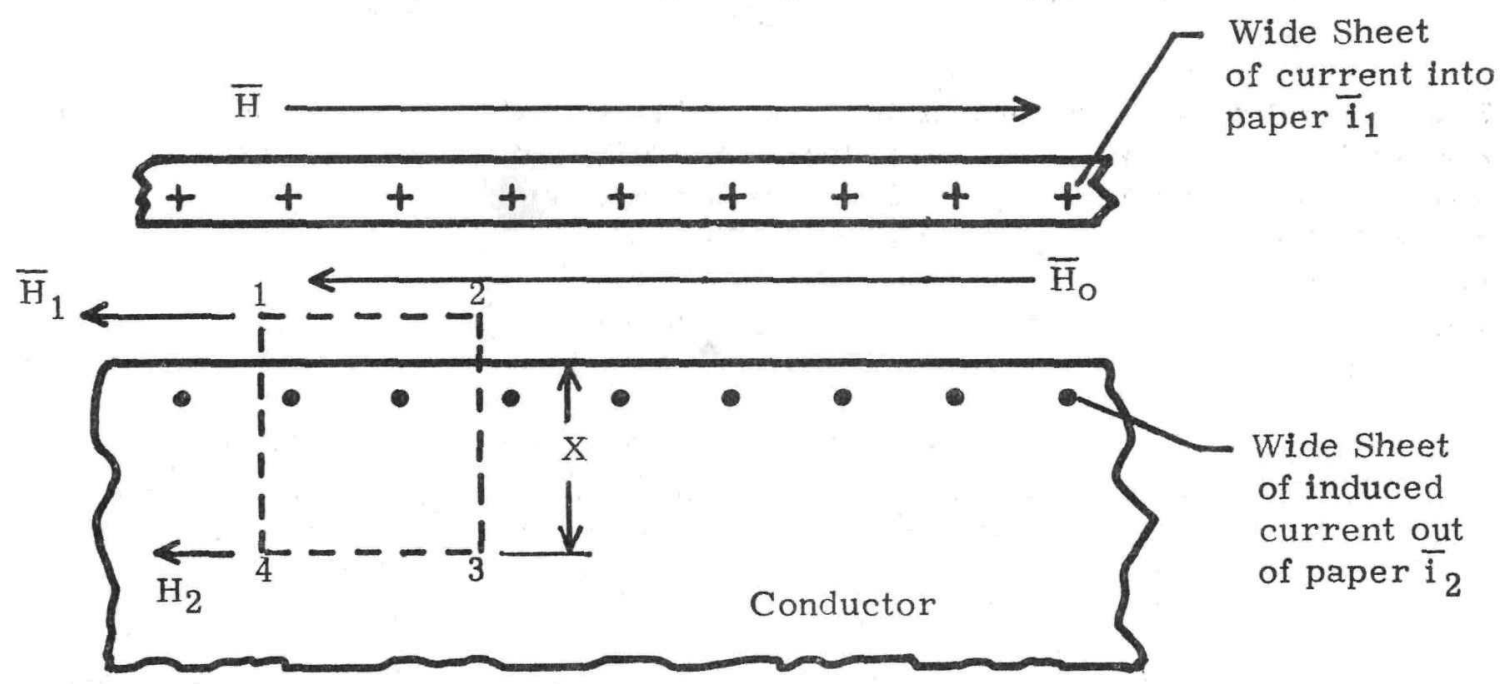

Figure 2. Basic Current-Field/Induced-Current Relationship

The magnitude of the current decreases exponentially versus the depth of penetration into the conductor. The value of $\sigma$ determines the depth at which the value of current has decreased to 1 /e (about 37 percent of the magnitude of the surface current).

Ampere's Circuital Law is applied (Reference 2) around path 1-2-3-4 to analyze the magnetic field intensity existing within the conductor. The total 
current enclosed may be expressed as the average current density times the conductor area enclosed by path 1-2-3-4. This is expressed as follows:

$$
\oint_{1-2-3-4} \overline{\mathrm{H}} \cdot \mathrm{d} \overline{\mathrm{I}}=\mathrm{I}=\left(\mathrm{i}_{2} \mathrm{avg}\right)\left(\text { Area }_{\mathrm{c}}\right) .
$$

In equation $2, \overline{\mathrm{H}}$ is the magnetic intensity vector in amperes/meter, 1 is the length in meters, I is the total current enclosed by the path, $\overline{\mathbf{i}}_{2(\mathrm{avg})}$ is the average current density expressed in amperes $/$ meters $^{2}$, and Area ${ }_{c}$ is the enclosed conductor area. Since all field contributions are parallel to the conductor surface, field contributions along paths 2-3 and 4-1 are zero, and equation 2 is evaluated as follows:

$$
\left(\overline{\mathrm{H}}_{1-2}\right)\left(1_{1-2}\right)+\overline{\mathrm{H}}_{3-4}\left(1_{3-4}\right)=\left(\overline{\mathrm{i}}_{2} \text { avg }\right)\left(\text { Area }_{\mathrm{c}}\right) .
$$

Therefore:

$$
\begin{aligned}
& \left(-\overline{\mathrm{H}}_{1}\right) \Delta \mathrm{1}+\overline{\mathrm{H}}_{2}(\Delta \mathrm{l})=\left(\mathrm{i}_{2_{\mathrm{avg}}}\right)\left(\text { Area }_{\mathrm{c}}\right) \\
& \overline{\mathrm{H}}_{1}-\mathrm{H}_{2}=-\frac{\mathrm{i}_{2} \mathrm{avg}\left(\text { Area }_{\mathrm{c}}\right)}{\Delta \mathrm{l}}=-\mathbf{i}_{2} \text { avg }(\mathrm{x}) .
\end{aligned}
$$

In equation No. $4, \mathrm{x}$ is the length of the path, normal to the surface, contained in the conductor and measured in meters. Equation No. 4 is a generalized expression for the attenuation of field intensity through the conductor in terms of the current distribution in the conductor. There are no restrictions on the location of the path around which the integration is to be performed. Therefore, if path length 1-2 is allowed to be outside the conductor, as shown in Figure 2, the value of $\overline{\mathrm{H}}_{1}$ becomes $\overline{\mathrm{H}}_{\mathrm{O}}$, which is the magnetic intensity vector existing in the air gap.

Now, consider the effect of allowing path lengths 2-3 and 4-1 to shrink to an infinitely small length, such that the entire path is contained within the conductor. The average current density then becomes the value of the current density. Thus from equation No. 4, the following equation results:

$$
\overline{\mathrm{H}}_{1}-\overline{\mathrm{H}}_{2}=\Delta \overline{\mathrm{H}}=-\overline{\mathrm{i}}_{2} \Delta \mathrm{x} \text {. }
$$

Expressed in differential form, this becomes:

$$
\bar{i}_{2}=\frac{-d \overline{\mathrm{H}}}{\mathrm{dx}} \text {. }
$$


Therefore, at any point within the conductor, the current density is equal to the negative rate of change of field intensity with respect to distance into the plate.

\section{Magnetic Field Force}

To determine the force exerted on the conductor, the force relationship existing between a current flow and a magnetic field is applied. In terms of current density, the force expression (Reference 3 ) per unit volume is given by:

$$
\frac{d \bar{F}}{d v} \bar{i} \times \bar{B}
$$

where $\mathrm{v}$ is the volume in the conductor.

The magnetic flux density vector $\overline{\mathrm{B}}$, expressed in webers $/$ meter $^{2}$ is given by:

$$
\overline{\mathrm{B}}=\mu \overline{\mathrm{H}} .
$$

Combining equations 6,7 , and 8 , the force per unit volume is given by:

$$
\begin{aligned}
\frac{d \overline{\mathrm{F}}}{\mathrm{dv}}=\overline{\mathrm{i}} \times \overline{\mathrm{B}} & =-\frac{1}{\mu} \frac{\mathrm{d} \overline{\mathrm{B}}}{\mathrm{dx}} \times \overline{\mathrm{B}} . \\
& =-\frac{1}{2 \mu} \frac{\mathrm{d} \overline{\mathrm{B}}^{2}}{\mathrm{dx}}
\end{aligned}
$$

Since the magnetic flux density is constant throughout any plane parallel to the conductor surface, equation No. 9 is expressed as:

$$
\begin{aligned}
& \frac{\mathrm{d} \overline{\mathrm{F}}}{\mathrm{dv}}=\frac{\mathrm{d} \overline{\mathrm{F}}}{\mathrm{d} \overline{\mathrm{d} x}}=\frac{\mathrm{d} \overline{\mathrm{p}}}{\mathrm{dx}}=-\frac{1}{2 \mu} \frac{\mathrm{d}^{2}}{\mathrm{dx}} . \\
& \text { Therefore } \quad \overline{\mathrm{p}}=\frac{-1 \overline{\mathrm{B}}^{2}}{2 \mu} .
\end{aligned}
$$

Equation No.10 is the expression, in rationalized mks units, for the "magnetic pressure, "expressed in newtons $/$ meters $^{2}$, exerted on a conductor in the presence of a time-varying magnetic field. The vector $\bar{B}$ is the magnetic flux density existing at the surface of the conductor. The validity of this equation rests on the fact that the current induced in the conductor prevents the field from leaking through the conductor. It can be shown that if the skin depth of the current is comparable to the conductor thickness so that the field appears on the opposite side, the current is decreased, resulting in less pressure on the conductor. This 
reaches a limit when the field on both sides is equal, resulting in no induced current and zero force.

Several sets of units are available and in use to describe electromagnetics. Up to this point only rationalized mks units have been used in this report to remain consistent with most texts on this subject. In practice, however, Gaussian or unrationalized cgs units are used more extensively. Therefore, the remainder of the report will use Gaussian units. Equation No. 10 would thus be modified to:

$$
\overline{\mathrm{p}}=-\frac{\overline{\mathrm{B}}^{2}}{8 \pi}
$$

where

$$
\begin{aligned}
& \bar{p}=\text { magnetic pressure in dynes } / \mathrm{cm}^{2} \\
& \bar{B}=\text { magnetic flux in gauss }
\end{aligned}
$$

There are several recent publications that are helpful in understanding theory and uses of magnetic pressure. Reference 4 presents a rigorous and thorough approach to the theory of magnetic forces and energies and the analogy between a magnetic field and a gas. Reference 5 shows that the efficiency of a system is high when the inductance change, created by the projectile motion, is relatively great when compared to the initial inductance.

\section{Test Setup}

\section{Description}

The primary consideration for this prototype unit was to demonstrate the feasibility of using the energy available from high-magnitude, transient magnetic field. Development costs were kept at a minimum and, whenever possible, existing materials were used.

The energy-storage component consists of a 24,000 Joule $(120 \mu \mathrm{f})$ capacitor bank, complete with operating controls. Figure 3 is a simplified diagram of the capacitor bank and controls. (In this figure, the conductor--projectile--is represented by a series L-R circuit that is mutually coupled to the magnet.) A wooden enclosure holds the magnet that produces the repulsion field. The magnet (Figure 4) is a flat, circular coil consisting of 30 turns of 0.5 -inch x 0.03 -inch copper strip separated by glass tape. The entire winding is encapsulated in a dielectric compound so that the edge of the copper winding is from 0.03 inch to 0.12 inch from the face of the coil assembly, depending on the actual thickness of the compound. The inner diameter of the coil is about 1-3/8 inches and the outer diameter is from 4 to $4-1 / 2$ inches. This results in self-inductance ranging from 40 to 65 microhenries, depending on the coil. The magnet assembly is about 1 -inch thick. The projectile used is a 2 -inch thick, $3-1 / 2$-inch diameter disc. A Kistler Model 802 accelerometer was mounted on the disc. The combined weight of the disc (projectile) and accelerometer was 1.96 pounds. 


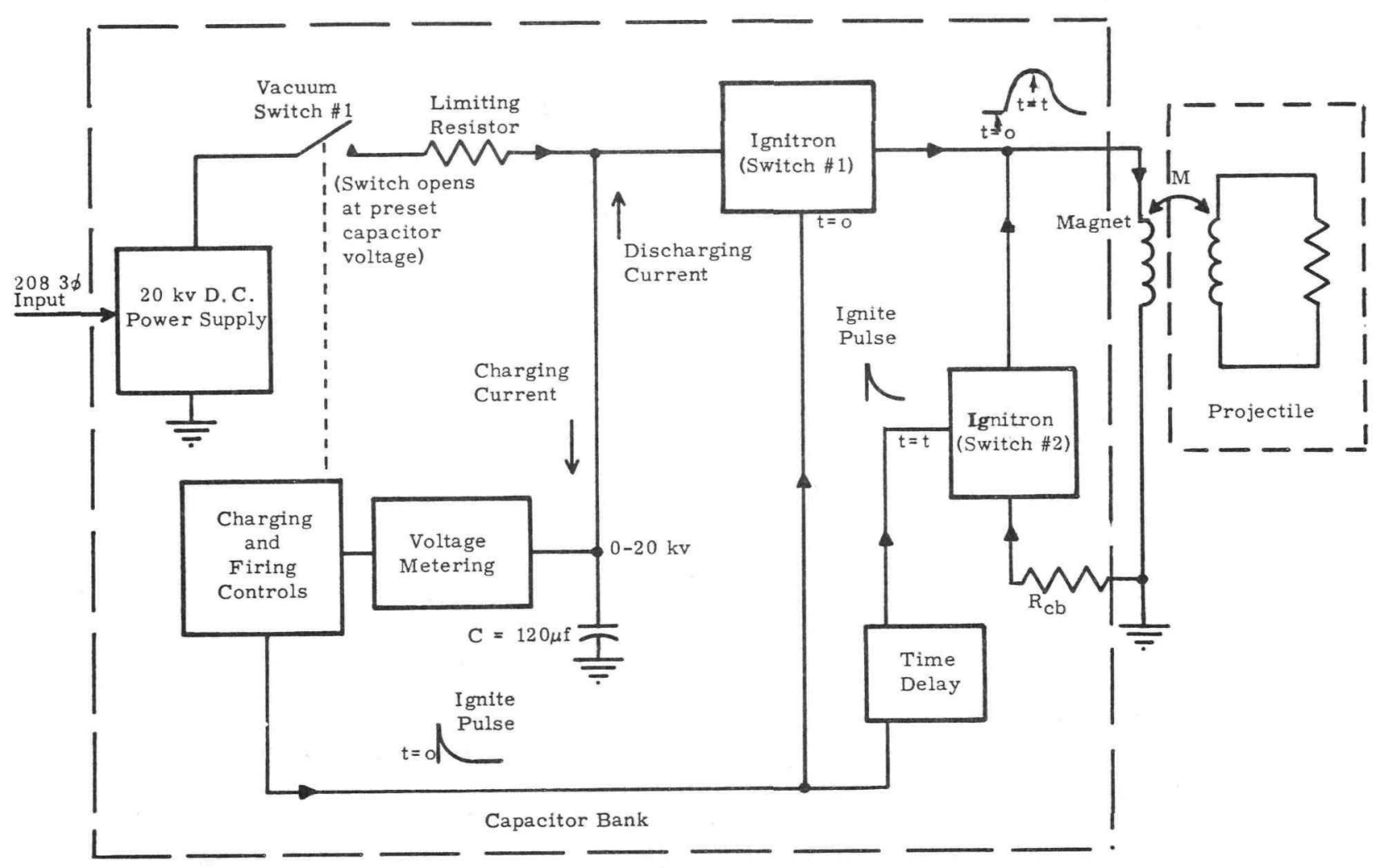

Figure 3. Block Diagram of Capacitor Bank and Controls

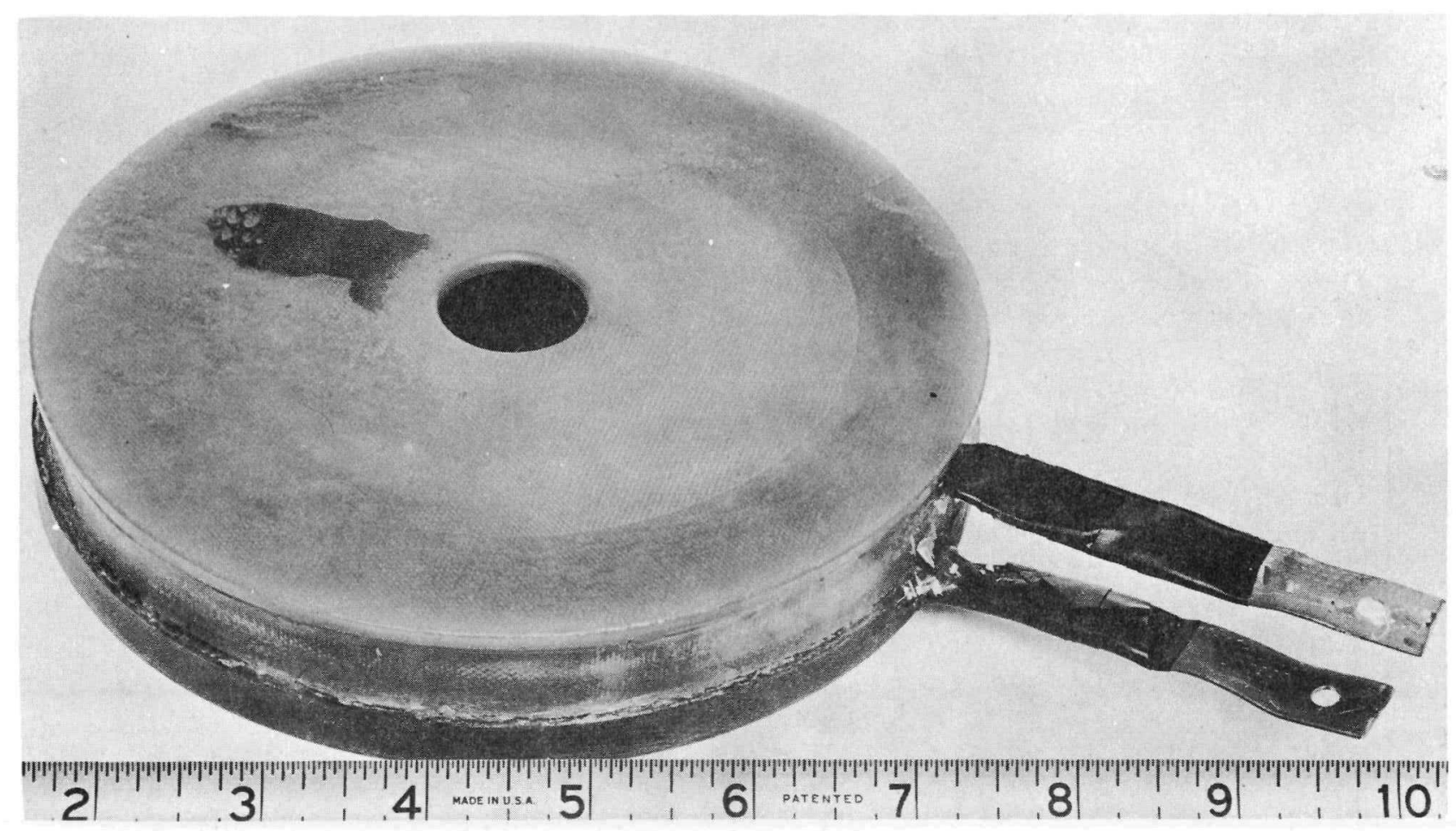

Figure 4. Encapsulated Magnet 
Projectile acceleration is monitored by the accelerometer on the center of the disc, away from the coil. Figure 5 is a sketch of the initial test setup. The projectile is held in place against the disc by a vacuum pulled through the center

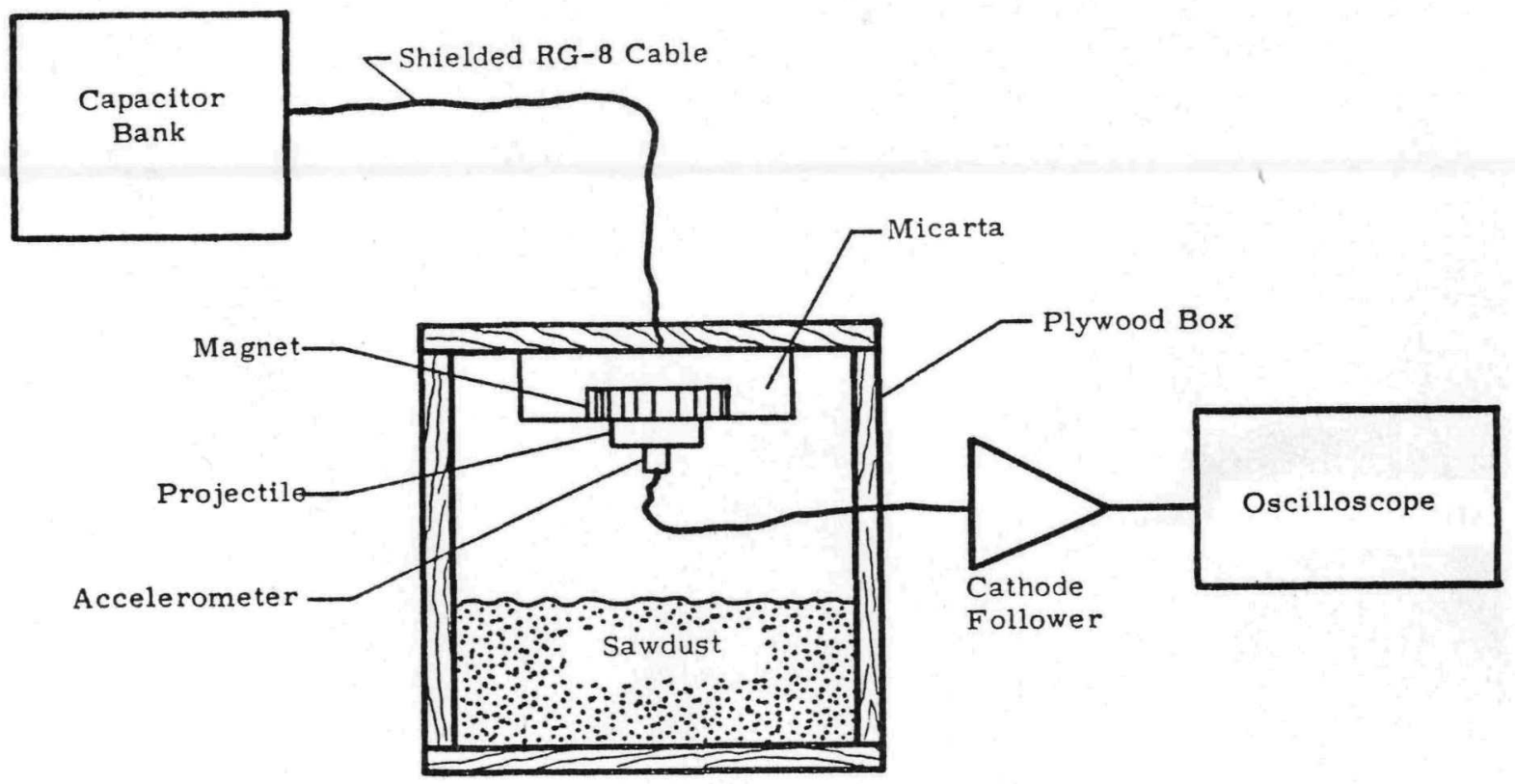

Figure 5. Simplified Diagram of Test Setup

of the coil. The accelerometer cable is Microdot No. 503804 and is allowed to hang down from the projectile. Kistler Model 802 accelerometers have been used because of availability and high-g rating. * Accelerometer output is fed through a Columbia Model 4000 cathode follower to a Tektronix oscilloscope to which a Polaroid camera is attached. The magnet is placed in a micarta block and bolted to the underside of the enclosure top, as shown in Figure 6 . The 2-inch thick plywood enclosure is filled with sawdust to within several inches of the disc. The capacitor bank is connected to the magnet through four shielded RG-8 cables, in pa rallel.

\section{Operation}

In practice, the projectile is installed on the magnet, and the vacuum switch is closed, allowing the capacitors to charge. Capacitor voltage is monitored through a metering circuit that causes the vacuum switch to open when the desired capacitor voltage is reached (see Figure 3 ). Since the ignitrons are in a

*Accelerometer specifications guarantee linearity to $10,000 \mathrm{~g}$ 's, so that assumption was made that the accelerometer output was linear with input magnitude. 


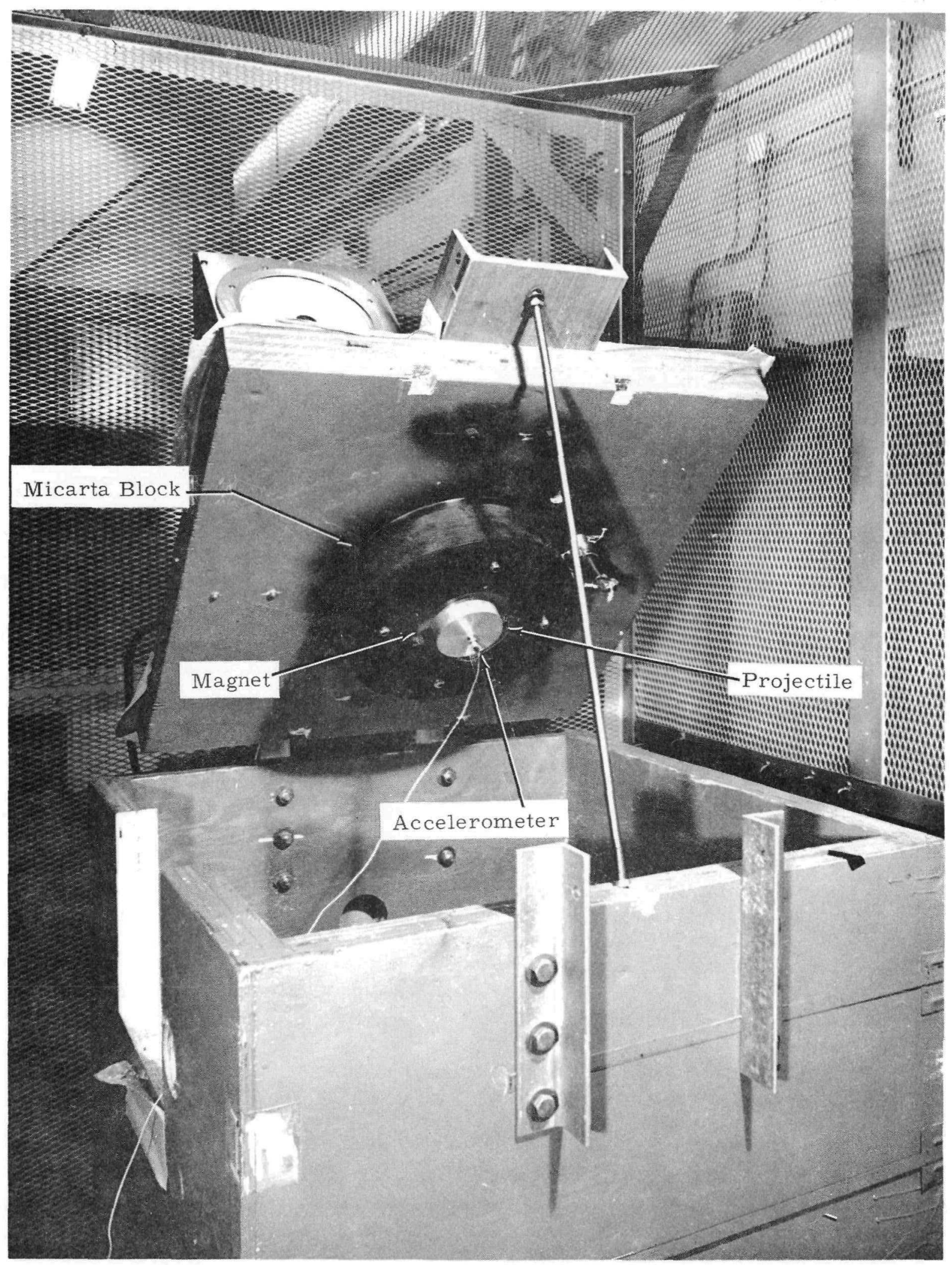

Figure 6. Test Setup 
nonconducting state, voltage is locked on the capacitors. When the selected voltage is reached, the capacitors are discharged through the coll by converting ignitron No. 1 to a conducting state. This is accomplished by sending an "ignite" pulse simultaneously to the ignitron and to a time-delay pulse generator. The current in the magnet rises sinusoidally until the quarter-cycle peak is reached, then the preset time-delay pulse generator ignites ignitron No. 2. The magnet is then short-circuited (crow-barred) through the second ignitron and $\mathrm{R}_{\mathrm{cb}}$. The short-circuiting operation maintains the direction of current flow, which then attenuates exponentially as described by the $L / R_{c b}$ time constant of the shorted circuit. The field generated by the magnet repels the projectile.

Figure 7 shows a cross-section representation of the current and field relationship of the magnet and the projectile. By holding the projectile close to the

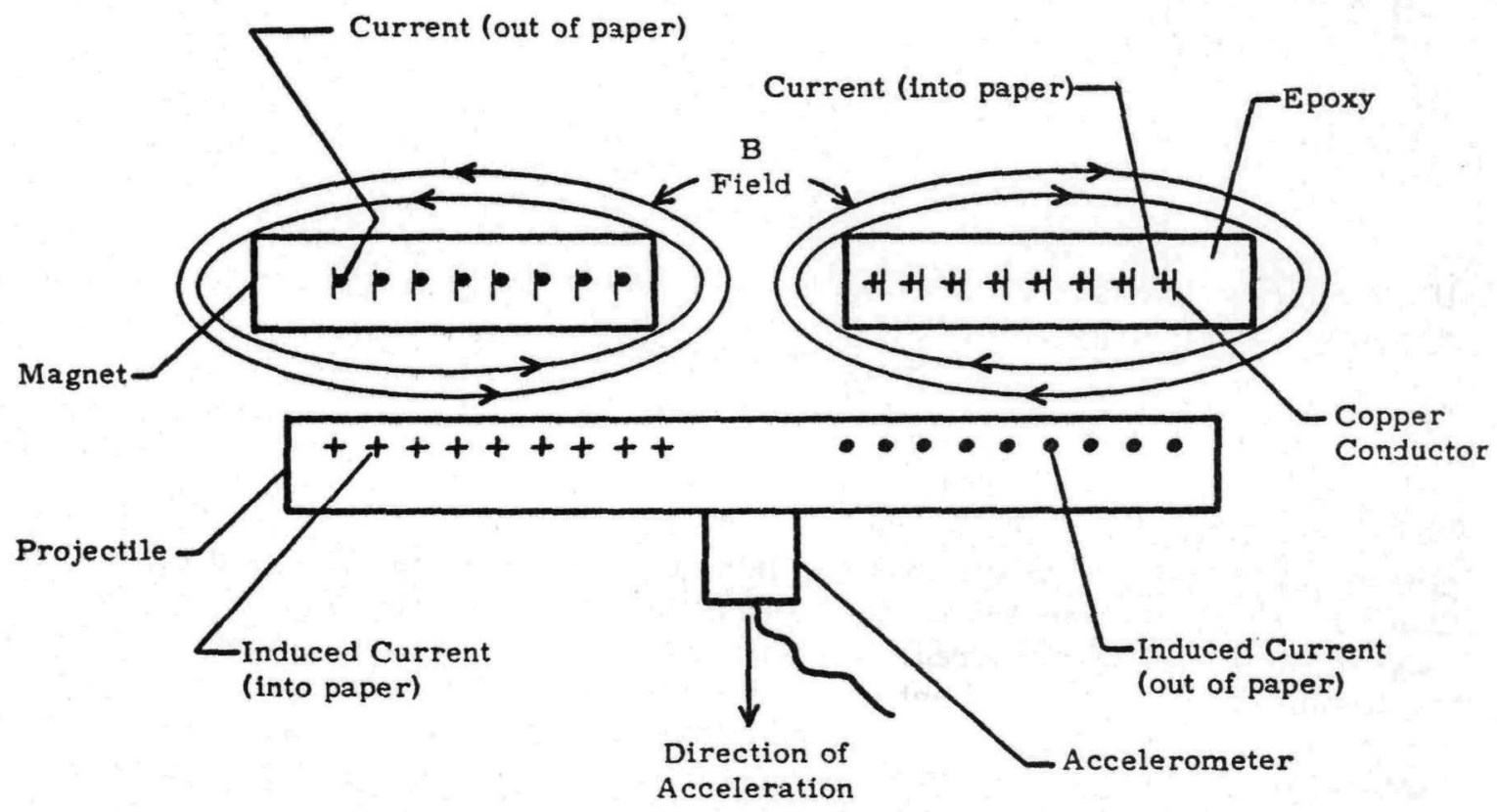

Figure 7. Cross-Section Showing Current and Field Relationship of Magnet and Projectile

windings, the flux lines essentially parallel the projectile surface, which then approximates an infinite-size source. However, the flux lines bend away from the projectile surface near the center of the projectile, resulting in a decreasing pressure in that area.

The energy contained in a magnetic field is given by:

$$
\mathrm{E}_{\text {nergy }}=\frac{1}{2} \mathrm{LI}^{2} \text {, }
$$

and the total flux contained is:

$$
\phi=L I
$$


Assuming a given energy input, a combination of the above two equations (No. 12 and 13) yields a flux relationship of:

$$
\frac{\phi_{2}}{\phi_{1}}=\sqrt{\frac{\mathrm{L}_{2}}{\mathrm{~L}_{1}}} \text {. }
$$

From an electrical system energy viewpoint, H. P. Furth (Reference 5) has shown that the maximum energy efficiency, up to the time of peak current, that may be realized is:

$$
\epsilon<\frac{\Delta L}{L_{O}+2 \Delta L}
$$

If the current is brought very rapidly to its maximum value and the coil is shortcircuited, the energy efficiency becomes

$$
\epsilon=\frac{\Delta L}{L_{O}+\Delta L} .
$$

where $\Delta \mathrm{L}$ is the inductance change during the acceleration pulse and $\mathrm{L}_{\mathrm{O}}$ is the inductance of the magnet (with the projectile in place) before the test. In either case greater efficiency is realized when $\mathrm{L}_{0}$ is lowered. In equation No. 15, a maximum of nearly 50 percent efficiency occurs as $L_{O}$ approaches zero. Also efficiency is lowered by the $\mathrm{I}^{2} \mathrm{R}$ energy losses occurring in both the primary circuit and the projectile. In Reference 1, it is shown that the power loss occurring in a plane conductor is given by the expression:

$$
\mathrm{W}_{\mathrm{L}}=\frac{1}{2} \mathrm{R}_{\mathrm{S}}\left|\bar{J}_{2}\right|^{2} \text {, }
$$

where $\bar{J}_{2}$ is the surface current density expressed in amperes/meter width and

$$
\mathrm{R}_{\mathrm{S}}=\sqrt{\frac{\pi \mathrm{f} \mu}{\sigma}} \text {. }
$$

Therefore, since the power loss is inversely proportional to the square root of the conductivity, a metal of higher conductivity for the projectile will consume less power with a given magnetic field. 


\title{
Instrumentation
}

The signal from the accelerometers is not filtered. Input to the magnet is monitored by measuring the current flow in the magnet. Magnet output is determined by measuring the field strength. Current flow is measured with a current-viewing resistor in series with the magnet. Field strength is measured by integrating the output of a pickup coil placed in the center of the magnet (Reference 6). Field strength against the projectile is a function of the volume between the magnet and the projectile and is not the same as the field strength in the center of the coil. However, the field strength against the projectile can be calculated within reasonable accuracy if the appropriate dimensions are known. Equation No. 13 shows that if the inductance remains constant, the current and field strength would have the same signature. Therefore, if both the current and field strength are monitored, the difference in waveforms will reflect the timevarying inductance change. This is shown in Figure 8. The flux $\phi$ represents an

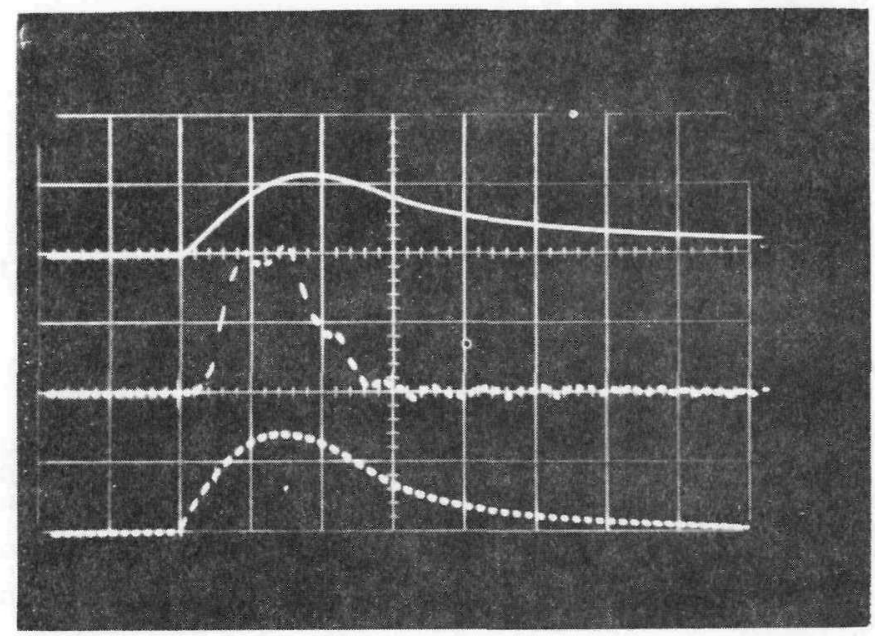

\author{
Top Trace - Magnetic \\ Flux $\phi$ \\ Middle Trace - Force \\ Bottom Trace - Magnet \\ Current \\ Time $\rightarrow(50 \mu \mathrm{sec} / \mathrm{cm})$
}

Figure 8. Field-Current-Force Relationship

integrated pickup coil in the center of the magnet. The current and accelerating force peak at nearly the same time and before the flux peaks.

As stated earlier, the acceleration force is monitored by a crystal accelerometer. It is significant that the projectile serves as a magnetic shield for the accelerometer, preventing an enormous signal (because of the field) from reaching the accelerometer.

Results and Conclusions

\section{Test Results}

Oscillograph readings are recorded in Figure 9. Table I provides data reduced from Figure 9. The peak accelerometer output was estimated and refers 


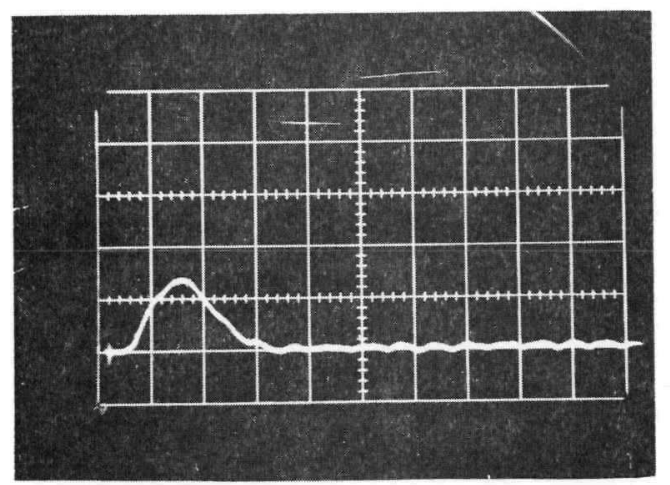

Accelerometer Sensitivity $=660 \mathrm{~g}^{\prime} \mathrm{s} / \mathrm{volt}$

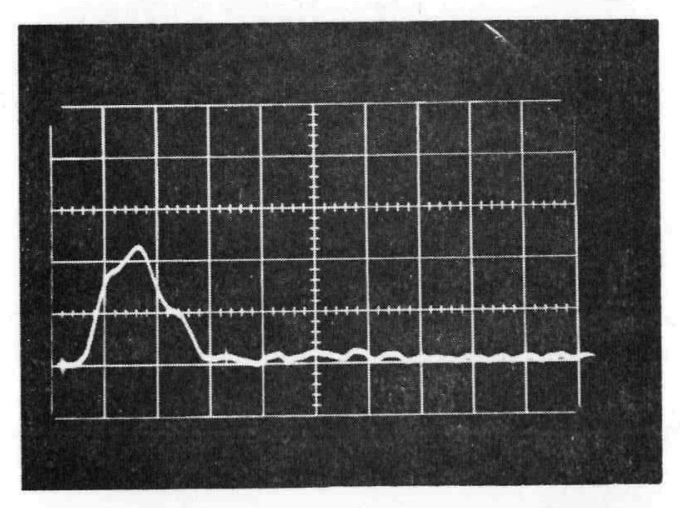

\author{
Capacitor Voltage $=2 \mathrm{kv}$ \\ Scope Sensitivity 2 volt/cm
}

\author{
Capacitor Voltage $=4 \mathrm{kv}$ \\ Scope Sensitivity $=5 \mathrm{volt} / \mathrm{cm}$ \\ $50 \mu \mathrm{sec} / \mathrm{cm}$
}
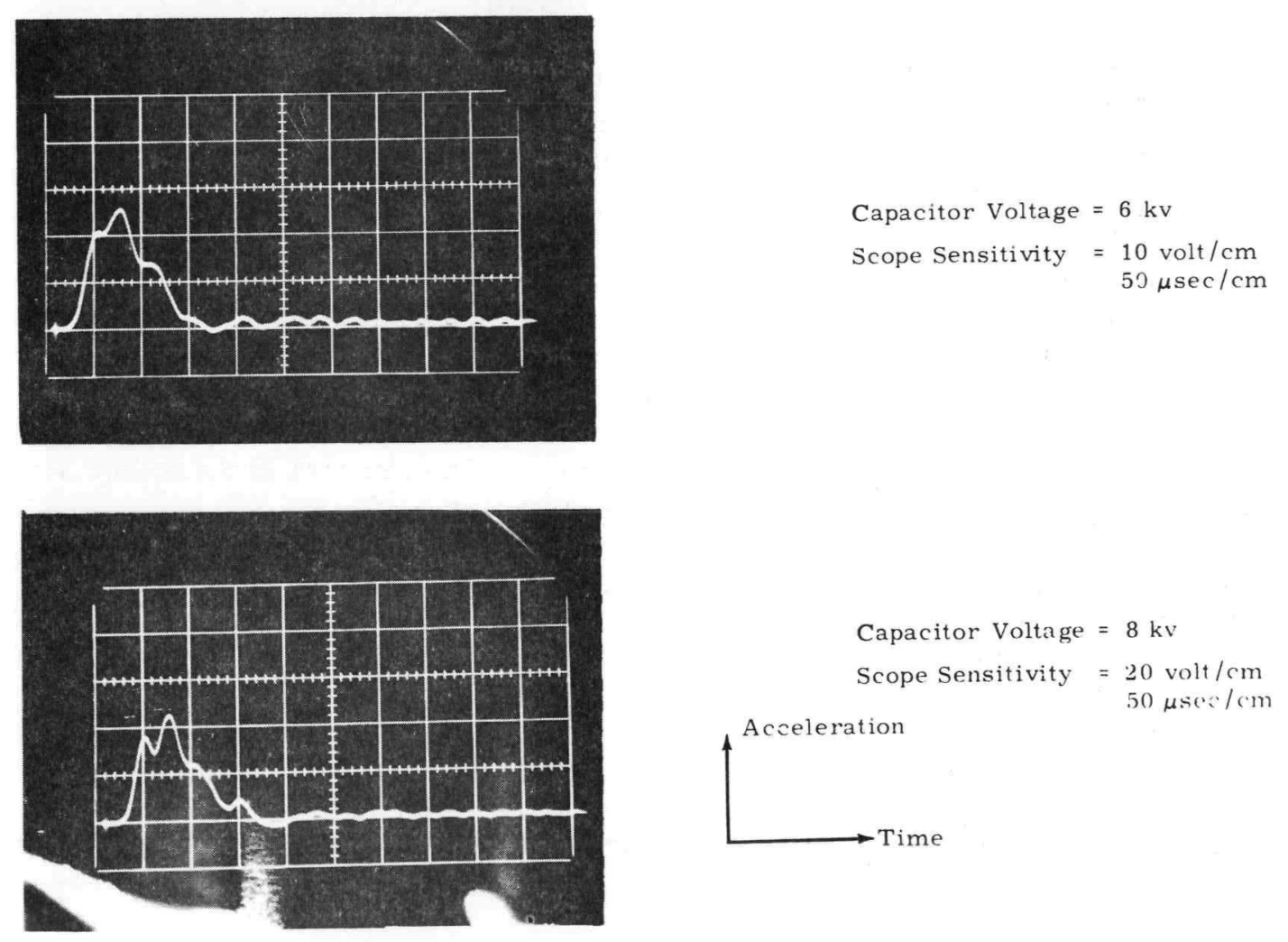

Figure 9. Unfiltered Acceleration Pulses at Various Input Voltages 


\section{TABLE I}

Data Tabulated From Figure 9

Accelerometer Kistler Model No. 802, Serial No. 205

Calibration - $660 \mathrm{~g}$ 's/volt

Projectile and Accelerometer weight - 1.96 pounds

\begin{tabular}{|c|c|c|c|c|c|}
\hline $\begin{array}{c}\text { Test } \\
\text { No. }\end{array}$ & $\begin{array}{c}\text { Capacitor } \\
\text { Voltage } \\
(\mathrm{kv}) \\
\end{array}$ & $\begin{array}{c}\text { Accelerometer } \\
\text { Output } \\
\text { (volts) }\end{array}$ & $\begin{array}{c}\text { Peak } \\
\text { Acceleration } \\
\left(g^{\prime} s\right) \\
\end{array}$ & $\begin{array}{c}\text { Peak } \\
\text { Force } \\
\text { (pounds) }\end{array}$ & $\begin{array}{c}\text { Time } \\
\text { Duration } \\
\text { (microseconds) }\end{array}$ \\
\hline 1 & 2 & 2.7 & 1,780 & 3,500 & 125 \\
\hline 2 & 4 & 11 & 7,270 & 14,300 & 125 \\
\hline 3 & 6 & 25 & 16,500 & 32,400 & 125 \\
\hline 4 & 8 & 44 & 29,000 & 57,000 & 125 \\
\hline
\end{tabular}

\begin{tabular}{|c|c|c|c|c|c|}
\hline $\begin{array}{l}\text { Test } \\
\text { No. }\end{array}$ & $\begin{array}{c}\text { Average } \\
\text { Acceleration } \\
\text { (ft/sec }{ }^{2} \text { ) } \\
\text { (assuming } \\
\text { half-sine } \\
\text { pulse) } \\
\end{array}$ & $\begin{array}{l}\text { Velocity } \\
\text { Final } \\
\text { (fps) } \\
\end{array}$ & $\begin{array}{c}\text { Projectile } \\
\text { Kinetic Energy } \\
(\mathrm{ft}-\mathrm{lb}) \\
\end{array}$ & $\begin{array}{c}\text { Stored } \\
\text { Capacitor } \\
\text { Potential } \\
\text { Energy } \\
\text { (ft-1b) } \\
\end{array}$ & $\begin{array}{c}\text { Energy } \\
\text { Efficiency } \\
\mathrm{KE} / \mathrm{PE} \\
(\%) \\
\end{array}$ \\
\hline 1 & 36,600 & 4.6 & 0.64 & 177 & 0.36 \\
\hline 2 & 149,000 & 18.6 & 10.5 & 707 & 1.5 \\
\hline 3 & 338,800 & 42.3 & 54.4 & 1590 & 3.42 \\
\hline 4 & 595,000 & 74.4 & 168 & 2830 & 5. 94 \\
\hline
\end{tabular}

to the amplitude of the primary pulse rather than the mechanical noise riding the pulse. The velocity was computed by assuming that the acceleration was a halfsine pulse. The kinetic energy was computed from the velocity (KE $=1 / 2 \mathrm{mv}^{2}$ ). Results were interpreted as follows:

1. Peak force (acceleration) is proportional to the square of the capacitor voltage. Since the magnetic field is proportional to the current, which is proportional to the voltage, it is expected that the force, a function of $\mathrm{B}^{2}$, is proportional to the square of the voltage. For this test, the force voltage relationship can be expressed as a parabola as follows:

$$
(\text { Force })_{\text {peak }}=\mathrm{K}(\text { Voltages })^{2} .
$$


The constant, $\mathrm{K}$, is found to be approximately:

$$
\mathrm{K}=890 \frac{\text { Pounds force }}{\text { (Kilivolt })^{2}} .
$$

Since the controlling parameters for the test are stable, electrical components, the output is highly predictable as well as repeatable. Based on the above data, a peak force of 89,000 pounds would be realized with an initial capacitor voltage of $10 \mathrm{kv}$.

2. The pulse time duration is independent of amplitude, but is dependent on both the frequency of the applied force and the distance of the projectile from the magnet. As noted previously, if the projectile remains close enough to the magnet. the magnet approximates an infinite-size source, resulting in little field attenuation versus distance between magnet and projectile. Therefore, in the case of the infinite source, the acceleration pulse is primarily influenced by the frequency of the magnetic field.

If the projectile is relatively far from a practical magnet, the field attenuates with distance, which gives the effect of a decreasing pulse width as the projectile moves.

The practical system tends to be self-compensating; i.e., as the projectile moves away, tending to decrease the pulse time, the inductance increases which increases the duration of the magnetic field.

3. Energy efficiency varies with the input energy which agrees with equation No. 15. As the input voltage is increased, the projectile is accelerated over a greater distance, resulting in a larger inductance change, $\Delta \mathrm{L}$. The self inductance of the coil used for this test series was $50 \mu \mathrm{h}$ with the projectile completely away from the coil and $30 \mu \mathrm{h}$ with the projectile in place. The values result in $\mathrm{L}_{\mathrm{O}}=30 \mu \mathrm{h}$ and $\Delta \mathrm{L}_{\max }=20 \mu \mathrm{h}$.

Equation No. 15 shows that maximum efficiency would be 28 percent for the values obtained. The high value of $\mathrm{L}_{\mathrm{O}}$, resulting in a low maximum efficiency, is due in large part to the 1/8-inch spacing between the winding and the projectile. In practice, the spacing need only be great enough to provide insulation. A spacing of 20 to 30 mils should be adequate for a $10 \mathrm{kv}$ test.

4. The signal-to-noise ratio of the acceleration pulse decreases as the acceleration increases during the time of the acceleration pulse. With a $2 \mathrm{kv}$ input, noise in the primary pulse is relatively insignificant. With $8 \mathrm{kv}$, the higher frequency noise is about 25 percent of the primary pulse. Since this phenomena varies in a predictable manner with projectile size, it is believed that the noise is a structural resonant frequency in the projectile. However, since the purpose of the over-all investigation has been energy conversion technique rather than optimum mechanical design, the noise phenomena has not been thoroughly investigated.

Because the magnetic field is a smooth function of about the same duration as the acceleration pulse, it would not be expected to excite the higher frequency. 
And since the projectile is mechanically free as soon as it leaves the surface of the magnet, it is not subject to mechanical noise excitation.

\section{Limiting Factors}

The amplitude and width of the force pulse are parameters of major interest. A primary limitation on the pulse amplitude is the ability of the magnet to withstand the combination of mechanical forces and electrical breakdown. The high field density in the magnet core exerts a high-radial, compressive stress on the windings at the same time the magnet receives the axially compressive reaction load (Reference 6).

Force Amplitude -- Mechanical strain promotes a turn-to-turn electrical breakdown that constitutes a coil failure.* However, the force amplitude is limited, for the present, by magnet strength. Coils used for this test have been reliable up to $8 \mathrm{kv}$; failures have occurred in the $10 \mathrm{kv}$ to $12 \mathrm{kv}$ range. **

Force Width -- Assuming that the width of the magnetic field pulse is completely variable, the maximum width force pulse is limited by the ratio of "skin depth" to projectile thickness, and/or the effective region of the magnetic field.

In the first case, it must be recalled that the skin depth is inversely proportional to the square root of the frequency. Therefore, if the applied pulse has a long duration (low frequency), the field penetrates farther into the conductor. If the field "leaks through" the projectile, the force is correspondingly reduced.

In the second case, if the projectile is accelerated over a large enough distance, the influence of the field is reduced. Minimum pulse time is dictated by the minimum time it takes to discharge the capacitor bank into a given load. With zero load impedance, a discharge time of 10 microseconds is easily attainable with standard capacitors. A discharge time of a fraction of a microsecond could be realized using better (lower inductance) capacitors. In practical application, the load impedance in conjunction with source impedance will determine the discharge time. If the circuit is allowed to oscillate, the frequency of the discharge pulse is calculated from conventional $\mathrm{R}-\mathrm{L}-\mathrm{C}$ circuit concepts. The oscillatory frequency of an underdampened R-L-C series circuit is given as:

$$
f=\frac{1}{2 \pi} \sqrt{\frac{1}{L C}-\frac{R^{2}}{4 L^{2}}} .
$$

This frequency can be used to determine the rise time, and if the magnet is crowbarred at peak current, the decay time will be determined by the L/R time constant of the discharge circuit.

*This report does not discuss magnet design considerations.

**Upon formal request by the author, Mr. A. R. Harvey of the Lawrence Radiation Laboratory, Livermore, is designing and will fabricate coils capable of withstanding higher mechanical and electrical stresses for specific application to this project. 


\section{Conclusions}

This investigation produced a predictable, repeatable, high-energy acce1eration pulse. The technique can be applied to produce a pulse duration throughout the 10 microsecond to 1 millisecond range.

Controllable forces of greater than 50,000 pounds are obtainable with the prototype shock device built for this investigation. A 50,000-pound force produces an acceleration of $100,000 \mathrm{~g}$ 's when applied to a $1 / 2$-pound projectile, or $1,000 \mathrm{~g}$ 's when applied to a 50 -pound projectile.

It is significant that the force pulse is monitored through an unfiltered, crystal accelerometer, yet produces a notably clean wave form.

The energy-storage system (capacitor bank) can be scaled upward to virtually any practical size, depending on economics. It is estimated that an energystorage system capable of producing a 10,000-g, 100-microsecond pulse on a 500 -pound item would cost about $\$ 25,000$ (or about $\$ 0.50$ per Joule). This estimate represents initial cost. When coupled with nearly negligible operating costs, the initial expense and operating costs of the equipment appear very low.

Since the capacitor bank is composed of a number of capacitors, relatively easy step-control in the pulse time can be achieved by varying the number of capacitors connected during a given test. Another method is to couple the magnet to the source through an impedance-matching transformer in which the ratio of secondary to primary turns is variable. In either case, vernier control can be achieved with a variable-size resistor in the circuit. As the circuit components are changed, the total energy in the circuit can be controlled by varying the voltage to the capacitors.

To date, a thorough investigation of projectiles has not been conducted. Aluminum and beryllium discs $1 / 2$-inch thick by $3-1 / 2$ inches in diameter have been compared and found equally efficient. However, the amplitude of the mechanical noise in the beryllium was considerably less and at a higher frequency because of the greater stiffness of that metal. Honeycomb-sandwich projectiles have been used for a number of tests and appear to have a good potential. The honeycomb serves to dampen the mechanical noise, and thelight weight of the projectile allows for high acceleration.

Continuing plans for development of the shock-test device include:

1. Control of pulse duration

2. Improved coil design

3. Minimize mechanical noise. 


\section{APPENDIX A -- REFERENCES}

1. Ramo, S. and Whinnery, J. R., Fields and Waves in Modern Radio, (2d Edition, John Wiley and Sons, New York, 1953, Chapter 6.

2. Rogers, W. E., Electric Fields, McGraw-Hill Book Company, New York, 1954, Chapter 9.11.

3. Hayt, Jr., W. H., Engineering Electromagnetics, McGraw-Hill Book Company, New York, 1958, Chapter 9.2.

4. Birdsall, D.H. ; Ford, F.C.; Furth, H.P.; and Riley, R.E.; "Magnetic Forming, "American Machinist, Vol. 105, No. 6, March 20, 1961.

5. Edited by Kolm, H. ; Lax, B. ; Bitter, F.; and Mills, R.; High Magnetic Fields, MIT Press and John Wiley and Sons, 1962, Chapter 22 "Pulsed Magnets" by Furth, H.P.

6. Furth, H. P. and Waniek, R.W., "Production and Use of High Transient Magnetic Fields I, "Review of Scientific Instruments, Vol. 27, No. 4, April 1956, pp. 195-203.

7. Lathan, B. F. and Radnik, J. L., "Electromagnetic Projector Study," Armour Research Foundation, April 1961.

8. Fitzgerald, A. E. and Kingsley, C. , Electric Machinery, McGraw-Hill Book Company, New York, 1952, Chapter 2 . 


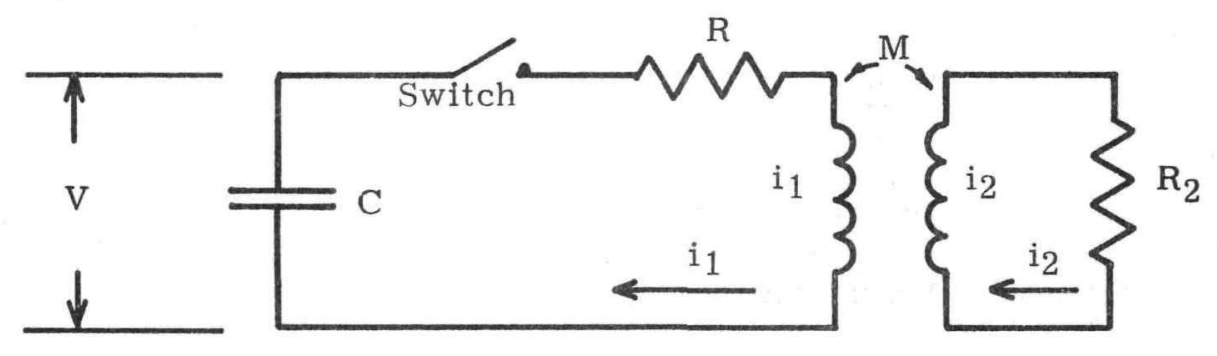

Figure B1

Figure B1 represents a circuit consisting of an underdampened series RLC primary and a secondary consisting of a series RL circuit inductively coupled to the primary. The capacitor, $\mathrm{C}$, is initially charged to a voltage, $\mathrm{V}$. When the switch is closed, primary current, $i_{1}$, induces a current flow in the secondary, $i_{2}$. The secondary then receives an acceleration force away from the primary. If the secondary circuit (the projectile) is unrestrained, the resulting displacement forms a changing mutual inductance. By applying conventional circuit theory and the conservation of energy, it can be shown (Reference 7) that the accelerating force is given by:

$$
f=-i_{1} i_{2} \frac{\partial M}{\partial x}
$$

where

$$
\begin{aligned}
& i_{1}=\text { instantaneous primary current in amperes } \\
& i_{2}=\text { instantaneous secondary current in amperes } \\
& M=\text { instantaneous mutual inductance in henrys } \\
& x=\text { displacement in meters } \\
& f=\text { force in newtons }
\end{aligned}
$$

The force of acceleration will always tend to separate the two circuits regardless of the initial voltage polarity or direction of primary current flow. 


\section{APPENDIX C -- FIELD ENERGY THEORY} by:

The energy density contained in a magnetic field is expressed (Reference 8)

$$
\mathrm{w}_{\mathrm{fld}}=\frac{1}{2} \frac{\mathrm{B}^{2}}{\mu}
$$

where

$$
\begin{aligned}
w_{f l d} & =\text { energy density in Joules } / \text { meter }^{2} \\
B & =\text { flux density in Webers } / \text { meter }^{2} \\
\mu \quad & =\text { permeability in rationalized mks units. }
\end{aligned}
$$

The total energy in a given field is then obtained by integrating equation 1C over the desired volume as follows:

$$
\mathrm{w}_{\mathrm{fld}}=\int_{\mathrm{v}} \frac{1}{2} \frac{\mathrm{B}^{2}}{\mu} \mathrm{dv} .
$$

The force available from the field may be expressed as the rate of change of energy with respect to distance when the flux is held constant. Consider an incremental volume, $d v$, as shown in Figure $\mathrm{C} 1$, consisting of an incremental cross sectional area $\mathrm{dA}$ and a depth of $\mathrm{dX}$ such that

$$
d \mathbf{v}=d \mathrm{Adx}
$$

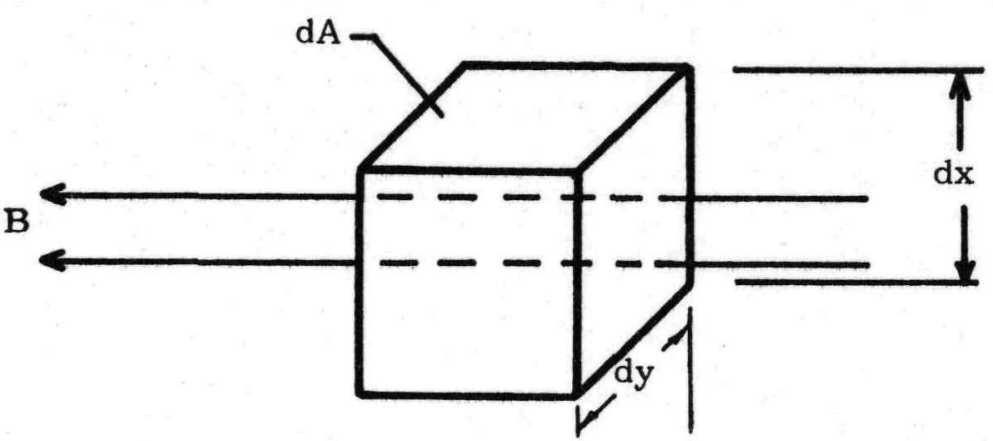

Figure C1

Let the incremental volume contain a uniform magnet flux density, B. In general, a force may be expressed as the rate of change of energy with respect 
to distance. Therefore, the force, expressed in terms of magnetic flux density, is given as:

$$
F=-\frac{d W}{d X}=-\frac{d}{d x} \int_{V=\text { constant }} \frac{1}{2} \frac{B^{2}}{\mu} d v \text {. }
$$

If dy is unity, then

$$
\phi=B A=B d y d x=B d x .
$$

Equation $4 \mathrm{C}$ is then evaluated as follows:

$$
\begin{aligned}
F_{\phi}=\text { constant }=-\frac{d}{d x} \int_{V} \frac{1}{2 \mu} \frac{\phi^{2}}{(d x)^{2}} \cdot d A d x \\
=-\int_{A} \frac{1}{2 \mu} \frac{d^{2}}{(d x)^{2}} d A=-\frac{1}{2 \mu} \frac{\phi^{2}}{(d x)^{2}} A \\
=-\frac{1}{2 \mu} B^{2} A .
\end{aligned}
$$

where $\phi$ is the total flux enclosed in the volume. The negative sign indicates that the force is a function of decreasing field energy. 